COMMENTARY

\section{Decolonizing the Caribbean diet: Two perspectives on possibilities and challenges}

\author{
Vanessa García Polanco a * \\ Michigan State University \\ Luis Alexis Rodríguez-Cruz ${ }^{b}$ \\ University of Vermont
}

\author{
Special JAFSCD Issue \\ Indigenous Food Sovereignty in North America \\ sponsored by \\ Swette Center for \\ Arizona State University
}

Submitted January 31, 2019/ Accepted February 1, 2019 / Published online October 15, 2019 /

Corrected to cite sources on second page, December 3, 2019

Citation: García Polanco, V., \& Rodríguez-Cruz, L. A. (2019). Decolonizing the Caribbean diet:

Two perspectives on possibilities and challenges. Journal of Agriculture, Food Systems, and Community

Development, 9(Suppl. 2), 25-30. https://doi.org/10.5304/jafscd.2019.09B.004

Copyright (C 2019 by the Authors. Published by the Lyson Center for Civic Agriculture and Food Systems. Open access under CC-BY license.

\begin{abstract}
We wonder if food and agriculture will be an emergent theme in reclaiming the identity of the Taíno, the Indigenous people of the Caribbean. As we consider the emergent movement to decolonize our diets and utilize food as medicine alongside veganism and vegetarianism trends, we wonder how and if food, foodways, and agriculture are or will be tools to decolonize and reclaim the Taíno identity. In this paper, we will explore two perspectives on the possible opportunities and

a * Corresponding author: Vanessa García Polanco, Department of Community Sustainability, Natural Resources Building, Michigan State University; 480 Wilson Road Room 131; East Lansing, MI 48824 USA; +1-401-545-2581; garci430@msu.edu

b Luis Alexis Rodríguez-Cruz, Food Systems Program, Graduate College, University of Vermont; 256 Carrigan Wing, Marsh Life Sciences; Burlington, VT 05405 USA; +1-802-6562042; lrodrig2@uvm.edu
\end{abstract}

challenges of such movements and how they will look in the Caribbean and its diaspora.

\section{Keywords}

Caribbean Foodways, Caribbean Diet, Dominican Republic, Puerto Rico, Taíno

\section{Introduction}

The narrative of popular history holds that soon after Christopher Columbus arrived in the Caribbean in 1492, the Taíno, the Native American inhabitants of the region, were almost completely decimated by slavery, disease, starvation, and war. In Cuba, Jamaica, Haiti, the Dominican Republic, Puerto Rico, and the Lesser Antilles, 90\% of the Native population may have died within a half century (Smithsonian Global, 2018). While the study of the conquest has generally focused on the social, political, and economic devastation inflicted on Indigenous populations such as the Taíno, the 
matter of food is rarely considered (Smithsonian Global, 2018). Yet food was a principal tool of colonization. Arguably, one cannot properly understand colonization without considering the many ways that food has been used as a tool to colonize the body and the mind, as well as the physical landscape. Although today we can recognize many Indigenous foods as staples of Latin American diets, we must also acknowledge the legacy of colonization in this diet (Alvarez, 2018). Primary accounts documenting the process of colonization in the Caribbean, especially in its largest island, formerly known as Kisqueya or Quizqueya and renamed Hispaniola by the Spaniards (today Haiti and the Dominican Republic), recount the impact of inadequate food for the Taínos. The early impact of famine and malnutrition on the Taíno is not well understood, but extreme labor with inadequate supplies of food and tainted water led to dehydration, malnutrition, and, at times, outright starvation. The conquistadores' diet that the Taínos were forced to eat was inadequate, and the conquistadores attributed the death of many Taíno to the strain of traveling between the mines and the change in their diet (Cook, 2002).

Nevertheless, many Taíno words that can still be found in the Caribbean relate to foodstuffs and agricultural production, thus continuing to transfer native knowledge. An example is casabe, a flatbread made from yucca or cassava flour. Other prominent examples are the traditional house style called a bohio, made with local materials that are weather-resistant, and the conuco, the garden plot (Palmer, 2018). In the beginning of the $20^{\text {th }}$ centrury, during an ever-changing socio-economic and political landscape, these traditional practices helped rural Caribbean resident with limited funds to build their own homes and feed themselves (Palmer, 2018).

The erasure and lack of recognition of Taíno foodways and culture as part of the mainstream Caribbean culture concerned us. We set sail to discover what already exists, since it has always been there: a movement hoping to conserve and revive Taíno identity and culture across the Antilles.

How do you revive and reclaim cultural practices when the world thinks they disappeared hundreds of years ago? That is a question explored in the "Taíno: Native Heritage and Identity in the Caribbean," a new exhibition by the Smithsonian National Museum of the American Indian and the Smithsonian Latino Center and through a team under the name the Caribbean Indigenous Legacies Project. This team is also conducting research on what it calls "resurgent indigeneity":

What it means to "be" or "become" Indigenous for a people who are not typically seen, or who are no longer accepted, as Indigenous. To do this, [they are] investigating Indigenous consciousness among Antillean Latinos, particularly among Puerto Ricans who are recovering an Indigenous Taíno heritage, reclaiming Taíno identity, and reconstituting Taíno community. (Marigny, 2016, para. 3)

As we consider an emergent movement such as the one described above, we wonder how and if food, foodways, food sovereignty, and agriculture are or will be tools to decolonize and reclaim the Taíno identity in the Caribbean and its diaspora of approximately 4.4 million Caribbean immigrants in the United States (Zong \& Batalova, 2019). In this paper, we will explore two perspectives on the possible opportunities and challenges of such movements and how will they look in the Caribbean and its diaspora.

\section{Perspective 1}

\section{Caribbean Food and Diet With or Without Taíno Reclamation?}

\section{Vanessa García Polanco}

I started my inquiry about Tainidad - what is to be Taíno? What is it to be Taíno today? - with the subjects of food and agriculture, knowing that Taínos praised the god Yocahu as the giver of yuca (cassava). That led me to further consider why and how yuca is no longer the praised tuber it once was in the Taíno Caribbean, when other tubers like potatoes associated with western foodways are taking a stronghold.

Variations of the Caribbean diet have existed traditionally across the more than 20 islands and 
nations that make up this territory where over 40 million people live. Our eating pattern is a blend of the broad traditional diets of major cultures: the Indigenous people, the Spanish, and continental Africans (Oldways, 2018). At the moment of conquest, the Taíno cuisines were rather simple, yet the foodways of the Caribbean are the ones most similar to those of Spain (Raichlen, 1998). The Spanish-speaking Caribbean (Cuba, Puerto Rico, and the Dominican Republic) shares a similar food culture, a rising concern over growing obesity rates, and increased consumption of energy-dense and ultraprocessed foods, but as nations, we differ in our current economic and political conditions (Fuster, 2016). Spanish-speaking Caribbean countries are characterized by traditional dietary patterns, where rice and beans are staples and reaffirm the Caribbean identity (Ortiz Cuadra, 2013). Today, a variety of ultraprocessed foods and drinks, including sugar-sweetened beverages, are ever-present and constitute add-ons to traditional diets. These products are cheap and widely available due to local manufacturing or better trade conditions, and are becoming more ingrained in local food cultures. While current diets tend toward energy-dense foods, an increase in the consumption of pre-prepared food products and foods away from home has resulted in a lower consumption of fruits and vegetables (Fuster, 2016). In my own childhood, merienda (snack time), between ten and eleven AM for school recess and between three and five PM, was marked by the consumption of snack foods as papitas or chips, sometimes potato chips, plantain chips, or cornbased fandangos and hojuelitas. Other snacks included sugar cookies, chocolate and cream cookies, a local baked good, an imported chocolate bar, other local flour-based snacks, and a refresco, or soda, usually from a local company or perhaps an American brand. Thus, although endemic fruits were largely available year-round, my palate was not trained to favor them or see them as a snack or a major component of my diet. Perhaps it was my privilege as a middle-class Dominican in a city, who thus could afford these high-sugar and high-calorie snacks, or my family's willingness to satisfy the picky eating behavior that prevented me from trying and learning to consume many fruits and vegetables that are part of my food culture and native to the Dominican Republic that only now I am willing to eat.

An answer to this could be that the Caribbean might be on a path to, or is already experiencing, what many communities do to resist a change in their diet due to an influx of "unnatural foods"using food as medicine, as food-based solutions are utilized for chronic disease prevention and management. Often there is a call to go "back to your roots": to eat traditional foods, to eat fewer foods that were adopted during the colonization process, and to acknowledge how processed foods have affected our diets. In the U.S., we see food as medicine as a niche as minorities, immigrant, and Indigenous communities are reclaiming their ancestral foodways. Publications such as Calvo and Esquibel's Decolonize Your Diet: Plant-based MexicanAmerican Recipes for Health and Healing guide readers to explore and reclaim their indigenous foodways as an act to decolonize their diet, use food as medicine, and reclaim Native American heritage. I am concerned, however, that in an attempt to use food as medicine in the Caribbean, we might forget about the necessary process of decolonizing our diet as a whole and may just perpetuate a new kind of food imperialism and culinary colonization (Steckley, 2016). This could happen if many more people were to adopt food as medicine and rather than choosing pre-contact Taíno foods such as cassava, batata, corn, beans, guanabana, jagua, guayaba, and mamey (Moscoso, 1999), were instead to choose potatoes, tomatoes, spinach, grapes, avocado, citrus, wheat, and quinoa. While some of these fruits, vegetables, and cereals are native to the Americas and are currently present in Caribbean foodways, they are not specifically Taíno foods, so decolonizing one's diet and foodways in the Caribbean context does not really happen by becoming vegan or vegetarian. Focusing only on plant-based foods as the foundation for food as medicine and health could impose other foodways and cuisines such as Asian or Mediterranean, and western foods overall, as preferable to choosing a plant-based diet that is Caribbean or of Caribbean descent. There are already more than 10 self-identified vegan and vegetarian restaurants in the Dominican Republic and over 30 in Puerto Rico. With many more 
Caribbean vegan and vegetarian outlets in the places the Caribbean diaspora live, like New York City. Food choices often mark identity and legitimize social differences, and in the Caribbean who is willing to decolonize their diet and their reasons for doing it could further exacerbate and reinforce class hierarchies (Steckley, 2016), thus leaving low-income people and farmers of color out of the process.

A plant-based diet is not a full answer to reclaim Taíno foodways, however, since Taíno people also consume shellfish, fish, iguanas, and small rodents endemic to Hispaniola and the Antilles as part of their diet (Moscoso, 1999; Nold, Johnson, Conrad, Beeker, Kauffman, \& Elswick, 2009). At the same time, as eaters wanting to reclaim traditional Taíno foodways, we cannot ignore how those traditional foods are produced. We need to gain more knowledge of plants beyond foodstuff consumption and of agricultural practices to preserve and reclaim traditional ecological and agricultural knowledge. Nevertheless, we cannot decolonize our diets without decolonizing the agricultural system that is producing those traditional foods, our landscapes, our history, our bodies, our minds. Processes such as "recovery," "reclamation," "indigenization," and "decolonization" can be very different and diverse. Recovering Taíno foods may actually not be decolonizing, even if done widely, if certain cultural, social, and political changes do not occur.

\section{Perspective 2}

\section{Integrating New Knowledge into our Conversations About our Taíno Heritage}

\section{Luis Alexis Rodríguez-Cruz.}

One of the elementary school trips I vividly remember was when we visited the Centro Ceremonial Indigena de Tibes in Ponce, Puerto Rico (PR). It is one of the most important Taíno deposits of the Caribbean, and one of the most significant in PR (Curet \& Stringer, 2010). There we were shown how they lived, what some of their customs were, and we even also dressed up like them. It was not until I arrived at the University of Puerto Rico at Ponce that I started to better understand the Taíno history of PR beyond the superficial. Significant archeological sites can be found throughout PR, and according to historical records the archipelago had one of the largest established Taíno populations. Through my school years, it was very common, especially during La Semana de la Puertorriqueñidad, a week designated to celebrate Puerto Ricans diverse heritage, that I was reminded that all Puerto Ricans have Taíno, African, and Spanish blood flowing through our veins. It was (and maybe is still is) a very folkloric week. We would dance like jíbaros- that is what Puerto Rican peasants, or campesinos, are called, and is also misused to discriminatorily describe the ignorant or the poor. Today, it has a different connotation, and many groups have worked to reclaim jibaro as a sign of Puerto Rican pride and rooted values, since these people were strong and cultivated our lands. We would also listen to bomba, the Afro-Puerto Rican rhythm that makes everybody move to the beat of the drums. Moreover, we would experience Puerto Rican dishes. I do not recall being aware of the Taíno heritage of some of our dishes. Again, it was not until my days of higher education that I developed an awareness of Taíno history and began grasping their influences on our main dishes. What I do recall is how we were taught, in and out of school, how the Taínos were decimated, how lazy and naïve they were, and how they do not comprise a significant part of our heritage. Today, the work of geneticists (e.g., Schroeder et al., 2018) has become part of a wide range of scholarship, from history to archaeology, that is letting us know that these beliefs about the Taíno are not true.

The Taíno were an advanced people who contributed substantially to the Puerto Rican heritage. Not only did they combat the Spaniards' oppression, but they also contributed their culture to today's Puerto Rican customs and foodways. It seems that the Taíno were not totally obliterated, but that many integrated into the Puerto Rican identity. Recent research has shown that a significant percentage of Puerto Ricans carry Taíno genetic markers (Schroeder et al., 2018). And most of that heritage comes from Taíno women, likely because of forced integration by the colonizers.

Today's narrative is changing to one of inclusion and acceptance of a new reality. I understand 
that new scholarship could shape how we Puerto Ricans (and Caribbeans, more generally) are taught about the Taíno in our history, and thus concretize a robust presence in our views of the Puerto Rican and Caribbean heritages. Furthermore, understanding our identities beyond the trivialized "Puerto Ricans carry Spanish, African, and Taíno blood" can serve us to contest our own colonized mindsets.

'Colonialism' is a present word in PR. Today, PR is subject to a fiscal control board, appointed by the Obama administration, which has pushed for austere measures that affect Puerto Rican's wellbeing. The subject of Puerto Rico's status as an unincorporated territory of the US is a common one. Almost all Puerto Ricans have an opinion on whether PR should become a state of the US, seek sovereignty, or stay as it is. But the colony, beyond a sociopolitical framework, is also a mindset. How can I work to decolonize PR if I am still colonized? Understanding PR's reality, and my experience within that reality, has given me the opportunity to contest thoughts and ideas that have contributed to perpetuate the idea that PR is well as it is. Supporting local agriculture, recovering and reclaiming traditional knowledges and foodways, such as those from the Taínos, is one first step to contest that coloniality.

Today, I eat a pastel, a delicious dish made of a mix of tubers filled with pork or meat. My grandmother makes masa, a mixture of taro root, tropical squash, and green banana, seasoned with annatto and other spices and herbs. Then she spreads the masa on a flamed plantain leaf, puts pork in the center, wraps it, and boils it until ready. Puerto Ricans have a variety of mixtures and ways of preparing pasteles, but the principle is the same: a dish that not only has Spanish and Afro-Caribbean influences, but also Taíno (Ortiz Cuadra, 2013, 2018). I think of how tubers and achiote (a spice creating from local evergreens), traditional in Taíno foodways, are incorporated in the making of a pastel. Furthermore, that recovered and validated knowledge could serve us in better grasping the idea of decolonizing our diets by shaping our understanding of our diverse heritage.

Young Puerto Rican farmers and chefs who have an agroecological perspective are leading conversations about the importance of reshaping how we eat and farm so as to incorporate traditional food of our ancestors (e.g., Pagán-Roig, 2017). Processed foods, as well as those from fast-food chains, have been heavily integrated into the Puerto Rican diet since the 1950s. The rise of noncommunicable diseases in Puerto Rico and their impact on public health have been related to changes in diet and to sedentary lives. This reality should not be ignored if we want to bring back (and validate) traditional foodways.

Thus, eliciting new knowledge that clarifies our views of the Taíno, while also integrating actors within our local food systems, is essential in my view to building a starting platform that will serve us to better build a sociocultural awareness of the Taíno heritage in PR. Hence, if we want to start a movement on many levels that aims to decolonize our diets through validating our Taíno heritage, we must seek ways to incorporate and communicate that new knowledge of our Taíno reality into our conversations, and thus contest our coloniality.

\section{References}

Alvarez, L. (2018). Colonization, food, and the practice of eating. Cotati, CA: Food Empowerment Project. Retrieved from http://www.foodispower.org/colonization-food-and-the-practice-of-eating/

Calvo, L., \& Esquibel, C. R. (2015). Decolonize your diet: Plant-based Mexican-American recipes for health and healing. Vancouver: Arsenal Pulp Press.

Cook, N. D. (2002). Sickness, starvation, and death in early Hispaniola. Journal of Interdisciplinary History, 32(3), 349-386. https://doi.org/10.1162/002219502753364173

Curet, L. A., \& Stringer, L. M. (Eds.). (2010). Tibes: People, power, and ritual at the center of the cosmos. Tuscaloosa: University of Alabama Press.

Fuster, M. (2016). Comparative analysis of dietary guidelines in the Spanish-speaking Caribbean. Public Health Nutrition, 19(4), 607-615. https://doi.org/10.1017/S1368980015002153 
Marigny, E. (2016, January 20). Graduate student spotlight: Christina Gonzalez. Retrieved from the University of Texas Department of Anthropology website: https://liberalarts.utexas.edu/anthropology/news/article.php?id=10178

Moscoso, F. (1999). Sociedad y economía de los Tainos [Society and economy of the Taíno]. Rio Piedras, PR: Editorial Edil.

Nold, K. D., Johnson, C. C., Conrad, G. W., Beeker, C. D., Kauffman, E. G., \& Elswick, E. R. (2009, October). Utilizing shell middens as evidence of Taino food resources (Paper No. 242-12). Poster presented at Geological Society of America Annual Meeting, Portland, OR. https://gsa.confex.com/gsa/2009AM/finalprogram/abstract_164514.htm

Oldways. (2018). Latin American heritage diet. Retrieved from the Oldways, Cultural Food Traditions website: https://oldwayspt.org/traditional-diets/latin-american-diet

Ortiz Cuadra, C. M. (2013). Eating Puerto Rico: A history of food, culture, and identity (R. Davidson, Trans.). Chapel Hill: University of North Carolina Press.

Ortiz Cuadra, C. M. (2018, December 14). El pastel navideño y los libritos de cada quien [The diverse recipes of the Puerto Rican pastel during Christmas]. Retrieved from the 80 grados website: http://www.80grados.net/el-pastel-navideno-y-los-libritos-de-cada-quien/

Pagán-Roig, I. (2017, August 22). Cuando el ñame se sublevó contra las papas [When yam revolted against potatoes]. Retrieved from the Sabrosía website: https://www.sabrosia.pr/comida-saludable/2017/08/22/cuando-name-se-sublevo-las-papas.html

Palmer, A. (2018, August 23). This culture, once believed extinct, is flourishing [Blog post]. Retrieved from https://www.smithsonianmag.com/smithsonian-institution/culture-once-believed-extinct-flourishing-180970101/

Raichlen, S. (1998). Saludy sazón [English edition title: Healthy Latin cooking]. Emmaus, PA: Rodale Books.

Schroeder, H., Sikora, M., Gopalakrishnan, S., Cassidy, L. M., Delser, P. M., Sandoval Velasco, M., ... \& Willerslev, E. (2018). Origins and genetic legacies of the Caribbean Taíno. Proceedings of the National Academy of Sciences, 115(10), 2341-2346. https://doi.org/10.1073/pnas.1716839115

Smithsonian Global. (2018). The Caribbean indigenous legacies project: Celebrating Taino culture. Washington, D.C.: Smithsonian Latino Center. Retrieved from https://global.si.edu/success-stories/caribbean-indigenous-legacies-project-celebrating-ta \%C3\%ADno-culture

Steckley, M. (2016). Eating up the social ladder: The problem of dietary aspirations for food sovereignty. Agriculture and Human Values, 33(3), 549-562. https://doi.org/10.1007/s10460-015-9633-y

Zong, J., \& Batalova, J. (2019, February 13). Caribbean immigrants in the United States [Spotlight article]. Migration Policy Institute. Retrieved from https://www.migrationpolicy.org/article/caribbean-immigrants-united-states 